\title{
Successful Transcatheter Retrieval of the Embolized Coronary Stent During Primary Percutaneous Coronary Intervention
}

\author{
Mustafa Yurtdas ${ }^{\mathrm{a}, \mathrm{d}}$, Nesim Aladag ${ }^{\mathrm{b}}$, Yalin Tolga Yaylalic
}

\begin{abstract}
Stent dislodgement or embolization occuring during primary percutaneous coronary intervention (PCI) is a very seldom and potentially serious complication related to neurological events and peripheral arterial ischemia, loss of time and thus delayed optimal revascularization, resulting in worse outcomes. The most probable conditions associated with a higher risk of stent embolization are severe coronary lesion features (i.e., angulated vessel or calcified lesion), inadequate support of the guiding catheter, and physical properties of the stent used. Non-surgical and, if needed, cardiac or peripheral surgical retrieval techniques can be used for this complication. We report a case of embolization of a zotarolimus-eluting coronary stent into peripheral circulation during primary PCI and its successful retrieval using a snare catheter.
\end{abstract}

Keywords: Embolized stent; Primary percutaneous coronary intervention; Transcatheter retrieval

\section{Introduction}

Coronary stents have an important role in the practice of interventional cardiology by treating acute or threatening occlusive coronary disease or suboptimal dilatation after percutaneous coronary intervention (PCI) [1]. Dislodgement or embolization of a coronary stent before and/or in the stage of deployment is a rare but challenging complication, which is associated with loss of time and complications such as neurological events and peripheral arterial ischemia [2-5]. An embolized

\footnotetext{
Manuscript accepted for publication April 07, 2016

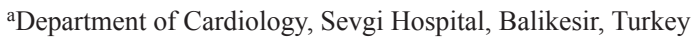

bDepartment of Cardiology, Van Region Training and Research Hospital, Van, Turkey

'Department of Cardiology, Pamukkale University, School of Medicine, Denizli, Turkey

${ }^{\mathrm{d} C}$ Corresponding Author: Mustafa Yurtdas, Department of Cardiology, Sevgi Hospital, Pasaalani Mah. 10020, Balikesir, Turkey.

Email: mustafayurtdas21@gmail.com
}

doi: http://dx.doi.org/10.14740/jmc2481w coronary stent may be lost in the peripheral or visceral arterial system with an incidence ranging from $0.29 \%$ to $8.4 \%$ [2-4]. Various devices and techniques can be used for the retrieval procedure [2-8]. Herein, we report a case of successful retrieval of a zotarolimus-eluting coronary stent embolized into the right posterior tibial artery (RPTA) using a snare catheter during primary $\mathrm{PCI}$ in a patient with acute inferior ST elevation myocardial infarction (STEMI).

\section{Case Report}

A 52-year-old gentleman with a past medical history of coronary artery disease presented to emergency department complaining of central chest pain for $1 \mathrm{~h}$. On arrival, he was distressed and sweaty, with blood pressure of 100/60 mm Hg. An electrocardiogram (ECG) showed a sinus rhythm, heart rate of $70 \mathrm{bpm}$, and $3 \mathrm{~mm}$ ST-segment elevation in leads II, III and $\mathrm{aVF}$, with the reciprocal changes. After premedication with antiaggregant and anticoagulation therapy, the patient emergently underwent a coronary angiography, which showed thrombotic occlusion of distal part of the proximal right coronary artery (RCA) (Fig. 1a). A 0.014 inch intermediary guidewire was passed through the occlusion into the distal vessel, ending up with thrombolysis in myocardial infarction (TIMI)-0/1 flow. After the lesion was predilated with $2.5 \times 12 \mathrm{~mm}$ sized balloon catheter, a zotarolimus-eluting stent (ZES) of $3.0 \times 18 \mathrm{~mm}$ was implanted, and full patency was achieved, but a second lesion proximal to the first stent considered to be long and severe despite intracoronary nitroglycerine administration was seen (Fig. 1b). Thus, the decision was made to stent the proximal part as well. While advancing, the stent was stuck and could neither be advanced through the lesion nor be withdrawn. Therefore, the whole system was withdrawn to the site of femoral sheath where the stent was detached from its balloon. The patient developed chest pain and the right leg pain. Lower extremity angiogram showed that the stent migrated down to the RPTA (Fig. 2a). First, the proximal part of the RCA was dilated with $3.0 \times$ $15 \mathrm{~mm}$ non-compliant balloon and, then stented with another ZES of $3.5 \times 30 \mathrm{~mm}$ using a $7 \mathrm{~F}$ AR-1 guiding catheter without any further complication (Fig. 1c). After removing $7 \mathrm{~F}$ sheath, an $8 \mathrm{~F}$ sheath was inserted through a new antegrade puncture of the ipsilateral common femoral artery. A $4 \mathrm{~F}$ multi-snare set (Nonnweiler, Germany) was advanced into the RPTA and the 

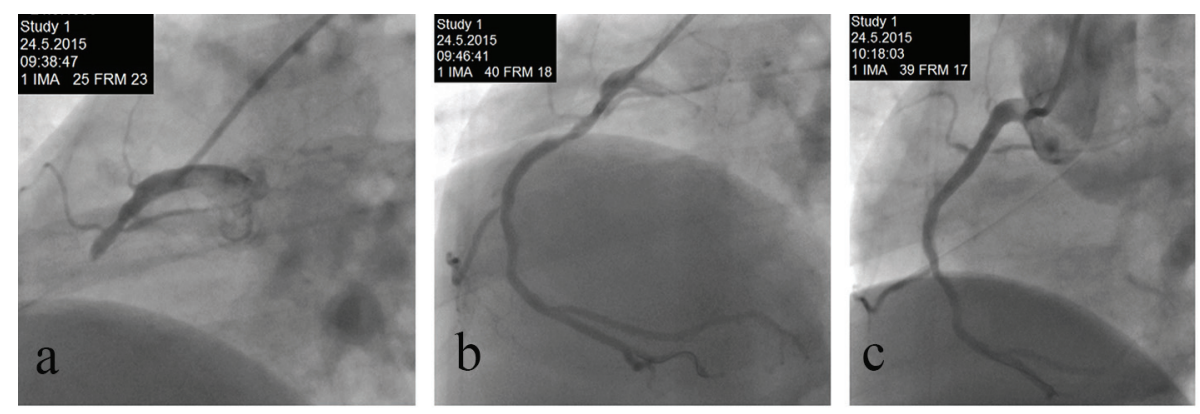

Figure 1. (a) Coronary angiography showing thrombotic occlusion of distal part of the proximal RCA. (b) Second long and severe lesion at the proximal to the first implanted stent in the RCA. (c) Successful stenting of the proximal part of RCA with another ZES of $3.5 \times 30 \mathrm{~mm}$ using a $7 \mathrm{~F} \mathrm{AR} 1$ guiding catheter.

stent was captured with the snare catheter (Fig. 2b). Then, the whole system was removed from the femoral artery (Fig. 2c). Post-angiographic course was uneventful with no signs of cardiac or lower limb ischemia.

\section{Discussion}

Coronary stenting has proved useful for the management of acute and chronic occlusive coronary diseases [1]. Dislodgement or embolization of a coronary stent before or during the deployment is an infrequent complication and may result in intracoronary or systemic stent embolization. While intracoronary embolization is associated with a high risk of coronary thrombosis and subsequent myocardial infarction, systemic embolization may cause severe cerebrovascular events, limb ischemia, death and the need for an emergency surgery [2-8].

Significant vessel angulation, severe calcified lesion, and poor support of the guiding catheter or the guidewire are among the main causes of the failure to deliver a stent, leading to increased risk of dislodgement or embolization [2-4]. In addition, flexibility, radial strength, structure, and shape affect the durability and deliverability of stents $[2,3]$. In our case, there was neither vessel calcification nor significant proximal angulation. However, we performed several methods to expedite stent deployment, such as selection of a guiding catheter with appropriate configuration for strong backup support, deep seating of the guiding catheter within the coronary artery, and relatively high balloon pressure to achieve sufficient coro- nary dilation before another long stent implantation. The most probable reasons responsible for undeployment of stent in our case are more severe lesion features than expected from angiographical data, inadequate support of the previous guiding catheter, and physical properties of the stent used. Although drug-eluting stents (DESs) are superior to bare metal stents (BMSs) as regards to major adverse cardiac events (generally defined as death, myocardial infarction, or the need for a repeat revascularization procedure) [9], to our knowledge, no reports have been published as to whether the use of DES or BMS makes a difference in terms of dislodgement or embolization. However, there have been several reports of dislodgement or embolization of a paclitaxel-eluting stent in the literature but not with ZES, making our case the first report $[5,8]$. In a previous study [8], paclitaxel-eluting stents had higher incidence of a lost or damaged stent than sirolimus-eluting stents or BMS, suggesting that premounting technology plays a crucial role in stent dislodgement from the device balloon. In another study [3], even though DES usage was low, no dislodgement or embolization had been reported with DES.

Systemic or coronary stent embolization during primary PCI may give rise to long delay times to optimal treatment. Early and timely revascularization reduces rates of recurrent ischemia, myocardial infarction and death in patients with acute coronary syndrome, with the greatest benefits realized in the highest risk patients [10]. In the case presented, the second ZES could not be deployed into the RCA due to the reasons discussed above. While the entire system was withdrawn to the level of femoral sheath as a single unit, undeployed coro-
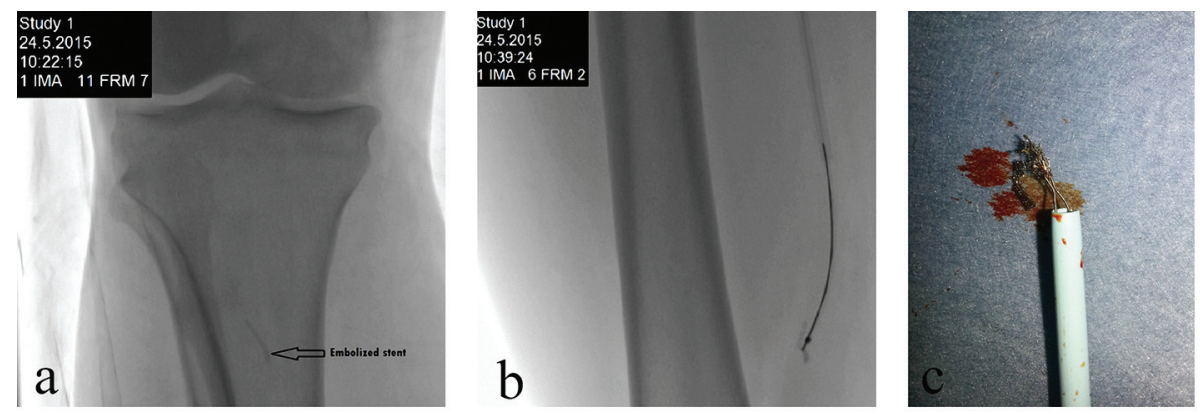

Figure 2. (a) Peripheral angiogram showing undeployed coronary stent embolized into the right posterior tibial artery. (b) Embolized coronary stent is captured with the snare catheter. (c) The retrieved stent. 
nary stent was observed to be stripped from its balloon and, then to be embolized into the RPTA, culminating in acute leg pain on top of the ongoing anginal chest pain. Initially, the culprit lesion in the RCA was fully revascularized with a goal of shortening the total ischemic time, and secondly, the embolized stent was sucessfully retrieved by a snare catheter.

There are several different techniques in managing cases of stent dislodgement or embolization [2-8]. Small-balloon method is often used when the dislodged stent remains on the guide wire: a low-profile balloon is placed distal to the stent through the dislodged stent and is withdrawn with the stent after inflating at low pressure. In the two-wire twisting method, the first wire is kept in place and a second wire is advanced through the stent struts as distally as possible. Afterwards, the two wires are twisted proximally with the stent straddling the stiff segments of the wires. Other retrieval devices are biopsy forceps, multipurpose baskets, and a loop snare. In case of failed retrieval of an embolized stent, another method used is to crush the stent against the vessel wall using another stent. Cardiac or peripheral surgery may be indicated if the retrieval or deployment method fails. In our case, we thought that the snare method could be easier and more suitable to capture the embolized coronary stent than other techniques.

In conclusion, this case illustrates that primary PCI can be complicated by an embolized stent. This condition might cause neurological events, peripheral arterial ischemia and delayed revascularization, resulting in less favorable outcomes. We were lucky that the stent was embolized to the leg. But we faced acute leg ischemia added on top of acute STEMI. We were able to retrieve the stent by a transcatheter technique after treating the coronary event. It is important to highlight that despite our successful percutaneous management of the embolized stent, each case should be evaluated based upon its own circumstances and merits, and the most appropriate therapy (i.e., transcatheter, surgical, or conservative treatment) should be carried out according to the patient-, vessel- and lesion-specific features.

\section{Conflicts of Interest}

There are no conflicts of interest related to this manuscript.

\section{References}

1. Al Suwaidi J, Berger PB, Holmes DR, Jr. Coronary artery stents. JAMA. 2000;284(14):1828-1836.

2. Brilakis ES, Best PJ, Elesber AA, Barsness GW, Lennon RJ, Holmes DR, Jr., Rihal CS, et al. Incidence, retrieval methods, and outcomes of stent loss during percutaneous coronary intervention: a large single-center experience. Catheter Cardiovasc Interv. 2005;66(3):333-340.

3. Colkesen AY, Baltali M, Acil T, Tekin G, Tekin A, Erol T, Sezgin AT, et al. Coronary and systemic stent embolization during percutaneous coronary interventions: a single center experience. Int Heart J. 2007;48(2):129136.

4. Alomar ME, Michael TT, Patel VG, Altomare CG, Rangan BV, Cipher D, Banerjee S, et al. Stent loss and retrieval during percutaneous coronary interventions: a systematic review and meta-analysis. J Invasive Cardiol. 2013;25(12):637-641.

5. Hondo T, Kisaka T, Sairaku A, Eno S, Matsuda K. Successful retrieval of a dislodged paclitaxel-eluting coronary stent in the abdominal aorta using a Gunther Tulip Vena Cava MReye Filter Retrieval Set. Journal of Cardiology Cases. 2010;1:e63-e65.

6. Eggebrecht $\mathrm{H}$, Haude $\mathrm{M}$, von Birgelen $\mathrm{C}$, Oldenburg $\mathrm{O}$, Baumgart D, Herrmann J, Welge D, et al. Nonsurgical retrieval of embolized coronary stents. Catheter Cardiovasc Interv. 2000;51(4):432-440.

7. Siani A, Siani LM, Mounayergi F, Baldassarre E. Lower limb ischemia after migration of a coronary artery stent into the femoral artery. Interact Cardiovasc Thorac Surg. 2008;7(3):447-448.

8. Roffi M, Luscher TF, Sutsch G, Maier W, Neuenschwanden C, Ramteke GB, Corti R, et al. Failure to retrieve undeployed paclitaxel-eluting coronary stents. Am J Cardiol. 2006;97(4):502-505.

9. Stefanini GG, Holmes DR, Jr. Drug-eluting coronaryartery stents. N Engl J Med. 2013;368(3):254-265.

10. Bagai A, Dangas GD, Stone GW, Granger CB. Reperfusion strategies in acute coronary syndromes. Circ Res. 2014;114(12):1918-1928. 